\title{
TEORIAS: REFERÊNCIAS OBRIGATÓRIAS PARA A REALIZAÇÃO DO TRABALHO CIENTÍFICO
}

\section{THEORIES: COMPULSORIES REFERENCES TO THE REALIZATION OF SCIENTIFIC WORK}

\section{Noêmia Lazzareschi}

\section{RESUMO}

Este artigo tem como objetivo demonstrar o significado das teorias como referências obrigatórias para a realização do trabalho científico. Fundamenta-se na obra de Thomas Kuhn e de Karl Popper, os mais renomados autores do campo da Filosofia da Ciência ao longo do século XX, cujas considerações sobre o processo de investigação científica e elaboração de teorias permitem aos estudantes ingressar mais facilmente no mundo do conhecimento academicamente sistematizado.

Palavras-chave: dogma; paradigma; investigação científica; anomalia; revolução científica

\begin{abstract}
This article aims to demonstrate the significance of theories as compulsory references for the development of scientific work. The study is based on the work of Thomas Kuhn and Karl Popper, the most renowned authors in the field of Philosophy of Science over the last century, whose comments on the process of scientific research and development of theories allow students to enter more easily into the world of academically systematized knowledge.
\end{abstract}

Keywords: dogma; paradigm; scientific research; anomaly; scientific revolution.

\footnotetext{
*Bacharel e Licenciada em Ciências Sociais pela USP; Mestre em Ciências Sociais do Trabalho pela Universidade Católica de Louvai, Bélgica; Doutora em Ciências Sociais pela UNICAMP; Profa. do Depto. de Sociologia e do Programa de Pós-Graduação em Ciências Sociais da PUCSP. E-mail: acyr.noemia@ terra.com.br
} 
No artigo A Função do Dogma na Investigação Científica, publicado alguns anos antes de seu texto mais conhecido e mais polêmico - A Estrutura das Revoluções Científicas - Thomas Kuhn afirmava que a existência de convicções fortes - de dogmas - antes da própria investigação aparece como pré-condições para o sucesso das ciências. Para ele, a atividade científica - ao contrário do que se poderia supor - é realizada no espaço fechado delineado por um paradigma (um conjunto de crenças dogmáticas) de investigação, de explicação teórica e de compreensão do mundo, aceito pela comunidade científica, cujos membros deixam de tentar opor-lhe rival ou de criar-lhe alternativas.

O paradigma determina todo um esquema de desenvolvimento para as ciências maduras ao definir os problemas legítimos e os métodos de investigação, isto é, ao informar sobre as técnicas que podem ser devidamente aplicadas na busca das respostas aos problemas legitimamente colocados, além de apresentar as soluções concretas destes problemas, indicando, portanto, o objetivo que se quer alcançar.

“... os praticantes duma especialidade científica madura aderem profundamente a determinada maneira de olhar e investigar a natureza baseada num paradigma. O paradigma diz-lhes qual o tipo de entidades com que o universo está povoado e qual a maneira como essa população se comporta; além disso, informa-os de quais as questões sobre a natureza que podem legitimamente ser postas e das técnicas que podem ser devidamente aplicadas na busca das respostas a essas questões. De fato, um paradigma diz tantas coisas aos cientistas que as questões que ele deixa para investigar raramente têm algum interesse intrínseco para os que estão fora da profissão.” (KUHN, Thomas, 1974, p. 67)

Não se trata, pois, de se considerar a atividade científica como uma atividade impulsionada pela fascinação de se explorar o desconhecido. Ao contrário. O que se busca é obter o conhecido.

“A fascinação deles (dos cientistas) é causada não pelo resultado que poderão vir a descobrir, mas pela dificuldade em conseguir mesmo o resultado. Em vez de se assemelhar a uma exploração, a investigação normal apresenta-se antes como o esforço de juntar um cubo chinês cujo aspecto final é conhecido desde o princípio.” (p.71)
E a atividade do cientista reduz-se à solução de quebra-cabeças, como um jogador de xadrez que obedece necessariamente a um conjunto de regras previamente formuladas. E tal como num jogo de xadrez, o fracasso na solução de quebra-cabeças deve ser atribuído à falta de habilidade do jogador.

“As regras fornecidas pelo paradigma não podem então ser postas em causa, uma vez que sem essas regras começaria por não haver puzzle para resolver. Não haja portanto dúvidas de que os problemas (ou puzzles), pelos quais o praticante da ciência madura normalmente se interessa, pressupõem a adesão profunda a um paradigma." (p. 71)

Embora tenha abandonado a palavra dogma por nela reconhecer um certo exagero retórico implícito, Thomas Kuhn, em A Estrutura das Revoluções Científicas, desenvolve aquelas mesmas ideias agora enriquecidas das noções de "ciência normal" e "ciência extraordinária" e aprofundando a noção de "anomalia", expressão primeira de uma crise científica cujo desfecho é a revolução científica, isto é, a mudança de paradigma.

O ponto de partida do trabalho científico nas ciências maduras é, pois, a adesão a um paradigma e o resultado deste trabalho é a "ciência normal", cuja tarefa é a de fazer frutificar o paradigma, estabelecendo uma adequação crescente entre as teorias e as experiências, o que reforça a unidade do paradigma.

“... De início, o sucesso de um paradigma (...) é, em grande parte, uma promessa de sucesso que pode ser descoberta em exemplos selecionados e ainda incompletos. A ciência normal consiste na atualização dessa promessa, atualização que se obtém ampliando-se o conhecimento daqueles fatos que o paradigma apresenta como particularmente relevantes, aumentando-se a correlação entre esses fatos e as predições do paradigma e articulando-se ainda mais o próprio paradigma." (KUHN, Thomas, 1975, p.44)

Não há discordância entre Kuhn e os demais filósofos da ciência, nem mesmo entre ele e Karl Popper com quem polemizou ao longo da vida, quanto ao fato de que os cientistas desenvolvem seus trabalhos dentro de uma estrutura teórica definida, ou seja, de um paradigma como a denomina Kuhn. É o próprio Popper quem o afirma:

“... há um edifício, uma estrutura organizada da ciência que fornece ao cientista uma situação - 
problema geralmente aceito a que o seu próprio trabalho pode ajustar-se. Isso se parece muito com um dos pontos principais de Kuhn: a saber, que a ciência "normal", como ele a chama, ou o trabalho "normal" do cientista, pressupõe uma estrutura organizada de suposições, ou uma teoria, ou um programa de pesquisas, necessário à comunidade de cientistas a fim de poderem discutir racionalmente o seu trabalho." (POPPER, Karl, 1979, p. 64)

Os filósofos da ciência são unânimes em afirmar que o trabalho de pesquisa científica se inicia com fundamento no conhecimento pré-existente, seja um conjunto de convicções mesmo sem caráter científico, seja uma teoria das ciências maduras, considerada verdadeira pela comunidade científica que a transforma num paradigma, isto é, na principal orientação para a investigação da realidade.

\section{O papel da teoria/paradigma}

Uma teoria - ou um paradigma - é um conjunto de afirmações explicativas, logicamente correlacionadas, sobre o comportamento dos fenômenos submetidos à investigação, ou melhor, sobre os problemas formulados a partir de sua observação. A teoria trata de responder às questões: $1^{\text {a }}$ ) quais fenômenos estão regularmente relacionados? quando estão relacionados? como estão relacionados? por que estão relacionados? As respostas a essas questões constituem as explicações científicas, cuja veracidade é indefinidamente testada pela pesquisa científica por elas orientada e que normalmente resulta no que Thomas Kuhn denominou "ciência normal": o resultado da pesquisa quase sempre comprova a veracidade da teoria por ter permitido ao pesquisador resolver os problemas por ela mesma suscitados com as soluções prévias nelas contidas, isto é, utilizando o esquema conceitual, classificações, correlações, generalizações, princípios, leis, etc., que a constituem. A ciência normal, portanto, resolve quebra-cabeças, problemas para os quais existe uma solução.

"Mas mesmo se o objetivo da ciência normal não consiste em descobrir novidades substantivas de importância capital e se o fracasso em aproximar-se do resultado antecipado é geralmente considerado como um fracasso pessoal do cientista - então por que dedicar tanto trabalho a esses problemas?
Parte da resposta já foi apresentada. Pelo menos para os cientistas, os resultados obtidos pela pesquisa normalmente são significativos porque contribuem para aumentar o alcance e a precisão com os quais o paradigma pode ser aplicado. Entretanto, essa resposta não basta para explicar o entusiasmo e a devoção que os cientistas demonstram pelos problemas da pesquisa normal. (...) Resolver um problema da pesquisa normal é alcançar o antecipado de uma nova maneira. Isso requer a solução de todo o tipo de complexos quebra-cabeças instrumentais, conceituais e matemáticos. O indivíduo que é bem sucedido nessa tarefa prova que é um perito na resolução de quebra-cabeças. O desafio apresentado pelo quebra-cabeça constitui uma parte importante da motivação do cientista para o trabalho." (Kuhn, Thomas, 1975, pp. 58/59)

As teorias existentes - paradigmas - são as nossas referências obrigatórias para a realização do trabalho científico pelas seguintes razões:

$1^{\circ}$ ) delimitam o universo da investigação porque definem o objeto de estudo de cada uma das ciências, e, em consequência, restringem os dados, os fatos, os fenômenos que devem ser observados e explicados, procedendo à determinação do que é significativo, isto é, dos problemas significativos a resolver; $2^{\circ}$ ) fornecem o esquema conceitual com o qual identificamos, por suas características particulares, os dados, os fatos, os fenômenos da realidade e as correlações entre eles, ou seja, as teorias fornecem o vocabulário próprio das ciências com a elaboração de neologismos que os identificam e que identificam também as correlações entre eles, o que em si mesmo supõe a sua classificação;

$3^{\circ}$ ) são o fundamento científico, portanto, seguro, da formulação de hipóteses norteadoras da investigação, hipóteses que também resultam da observação da realidade empírica, mas com o olhar orientado pelas teorias;

$4^{\circ}$ ) apontam os caminhos a seguir em todas as etapas da investigação, pois nelas está embutida a metodologia que lhes deu origem e que servirá de orientação para o prosseguimento do trabalho científico; $5^{\circ}$ ) elaboram generalizações empíricas e enunciam leis gerais, isto é, demonstram as relações constantes e imutáveis entre dados, fatos e fenômenos, o que significa que apontam os fatores causais dessas regularidades, razão pela qual poderemos prevê-los; 
$6^{\circ}$ ) demonstram as suas aplicações possíveis para a solução de problemas práticos, da vida cotidiana, o que torna o trabalho científico absolutamente pragmático, além de apontarem, segundo Goode e Hatt (1972), as lacunas no nosso conhecimento, pois sugerem onde nosso conhecimento é deficiente.

Karl Marx, Emile Durkheim e Max Weber são os autores dos três principais paradigmas das Ciências Sociais, em especial da Sociologia: o Materialismo Histórico e Dialético, o Positivismo Durkheimiano (origem do Funcionalismo) e a Sociologia Compreensiva, respectivamente. São as referências teóricas e metodológicas da pesquisa sociológica do século XX e deste início de século, apesar do reconhecimento de suas anomalias pela comunidade científica, isto é, apesar do reconhecimento de que não mais nos oferecem a solução adequada dos quebra-cabeças com que hoje nos defrontamos. Por isso, para muitos autores contemporâneos as Ciências Sociais estão em crise e é bastante significativo o número de publicações com este título, expressão da tentativa de superá-la seja com a formulação de novas teorias, ainda não declaradas paradigmas pela comunidade científica, seja com a demonstração pouco ou mesmo não convincente de que os antigos paradigmas oferecem, pelo menos parcialmente, a solução dos atuais quebra-cabeças.

Nas Ciências Sociais, especialmente na Sociologia, a competição entre perspectivas teóricas/paradigmas sempre foi rotineira em virtude da natureza mesma de seu objeto de estudo que possibilita diferentes modos de argumentação valorativa, ao passo que nas Ciências físicoquímico-naturais a experimentação limita e, em muitos casos, elimina, por razões óbvias, o dissenso entre os pesquisadores.

\section{As anomalias da teoria/paradigma, a crise na ciência e as revoluções científicas}

As teorias e/ou paradigmas, no entanto, têm como destino serem ultrapassadas, tornando-se antiquadas em curto espaço de tempo, em média, um século, segundo Thomas Kuhn. Se assim não fosse, não assistiríamos às crises nas ciências e às revoluções científicas. Quando as teorias/paradigmas levam à descoberta de fenômenos e/ou processos históricos novos e insuspeitados que não podem ser explicados com as orientações que elas encerram, quando a comunidade científica não consegue resolver os quebra-cabeças que as teorias/paradigmas lhe propuseram para explicar aqueles fenômenos e/ ou processos históricos, toma consciência de suas anomalias. Passa, então, a enfrentar um período de enorme insegurança profissional, ao duvidar da eficácia e eficiência das regras seguidas até aquele momento para a realização de seu objetivo: confirmar a veracidade do paradigma, fazendo ciência normal, resolvendo os quebra-cabeças que a pesquisa por ele orientada suscitou. Abre-se, em consequência, um período de crise do qual emerge um novo paradigma, um período marcado por investigações extraordinárias que conduzem os cientistas a um novo conjunto de compromissos, a uma nova base para a prática da ciência.

"Embora o cientista possa não ser um explorador, os cientistas estão sempre descobrindo tipos novos e inesperados de fenômenos. Embora o cientista não se esforce normalmente para inventar novos tipos de teorias fundamentais, tais teorias com frequência têm surgido da prática continuada da investigação. Mas nenhuma inovação desse gênero apareceria se a atividade a que chamei de ciência normal tivesse sempre êxito. (...) a prática científica normal de solucionar puzzles pode levar, e leva de fato, ao reconhecimento e isolamento de uma anomalia. Um reconhecimento dessa natureza é, penso eu, pré-condição para quase todas as descobertas de novos tipos de fenômenos e para todas as inovações fundamentais da teoria científica. Depois que um primeiro paradigma foi alcançado, uma quebra nas regras do jogo preestabelecido é o prelúdio habitual para uma inovação científica importante." (Kuhn, Thomas, 1974, PP. 73/74)

A crença nas possibilidades de um paradigma faz dele um paradigma único. Em princípio, o paradigma não tem rivais. $\mathrm{O}$ aparecimento de um novo paradigma significa o sepultamento imediato do velho. Como ambos são necessariamente incompatíveis, não podem coexistir.

$\mathrm{O}$ aparecimento de um novo paradigma deve-se ao fracasso caracterizado na atividade normal de resolução de problemas, ao aparecimento das anomalias que não são contraexemplos do paradigma, simples fatos, mas o reconhecimento explícito da natureza divergente das numerosas soluções parciais aos quebra-cabeças colocados 
pelo próprio paradigma. Esta é uma situação anormal e configura um estado de crise do qual emerge um novo paradigma. Isto significa que uma revolução científica é sempre um momento de ruptura total com o paradigma anterior e, ao contrário da ciência normal que é cumulativa, "as revoluções científicas são aqueles episódios de desenvolvimento não-cumulativo, nos quais um paradigma mais antigo é total ou parcialmente substituído por um novo, incompatível com o anterior.” (Kuhn, Thomas, 1975, p. 125)

Assim, a ciência normal, tal como definida por Kuhn, restringe-se à investigação e solução de problemas colocados pelo paradigma a partir dos instrumentos e conceitos por ele também proporcionados. É uma atividade absolutamente conservadora no sentido de que, ao dispensar a testabilidade do paradigma, apenas o reafirma. Com efeito, enquanto atividade que consiste em solucionar quebra-cabeças sugeridos e previsivelmente resolvidos pelo paradigma, a ciência normal não confronta teorias científicas e, portanto, dispensa o princípio da falseabilidade, isto é, dispensa tentativas de refutação, entre outros meios, pela observação e experimentação, situação inadmissível por alguns filósofos da ciência, sobretudo por Karl Popper:

"Em outras palavras, não exigirei que um sistema científico seja suscetível de ser dado como válido, de uma vez por todas, em sentido positivo; exigirei, porém, que sua forma lógica seja tal que se torne possível validá-lo através de recurso a provas empíricas, em sentido negativo: deve ser possível refutar, pela experiência, um sistema científico empírico. (Assim, o enunciado "Choverá ou não choverá aqui, amanhã”, não será considerado empírico, simplesmente porque não admite refutação, ao passo que será considerado empírico o enunciado "Choverá aqui, amanhã".) Popper, Karl: 1972, p. 42)

Isso significa que uma teoria/paradigma só será científica, de acordo com o pensamento de Popper, se puder ser contrariada por uma base empírica de fatos absolutamente firme para poder refutá-la, o que implicaria afirmar que a ciência cresce mediante o repetido derrubamento de teorias com a ajuda de fatos concretos. Mas, ainda segundo Popper, o enunciado básico incompatível com a teoria, e que é capaz de refutá-la, tem sua validade admitida por convenção da comunidade científica, não resultando da observação pura, sensível, da experiência direta, não dependendo, pois, do teste experimental, mas de dois fatos: primeiro, da aceitação pela comunidade científica de um conhecimento oriundo de um falsificador potencial, não da simples observação, e, segundo, deste conhecimento contrariar a teoria em causa.

Ou em outras palavras: segundo Karl Popper, as teorias científicas são hipóteses, conjecturas, suposições, formuladas a respeito dos fatos para descobrir a verdade, sem que jamais se possa dizer que efetivamente a descobriram. Formulada uma conjectura, o cientista deve tentar em seguida refutá-la buscando um enunciado que com ele seja logicamente incompatível (falsificador potencial) à luz dos resultados dos testes, experimentais ou observacionais, isto é, tenta falsificar a conjectura, rejeitando-a se puder fazê-lo e adotando-a provisoriamente caso não possa fazê-lo. Uma conjectura, quando suporta os testes da experiência e resiste à crítica racional, autoriza-nos a preferi-la a qualquer outra (provisoriamente e a título de ensaio), a supô-la ao menos mais próxima da verdade.

A rejeição ou adoção de uma conjectura como sendo melhor ou pior do que outra é o resultado da crítica racional, isto é, da análise crítica de sua consistência lógica e de sua resistência ao teste empírico. Essa crítica racional, constante e interminável, indefinidamente aberta, nos permite produzir razões válidas para questionar se uma teoria é ou não melhor do que outra.

No entanto, a ciência normal aceita a tese da necessidade não só de um referencial comum como também de uma estrutura comum que não se submete a críticas, pois o trabalho orientado por um paradigma só poderá ser conduzido da maneira por ele definida. É verdade que, segundo Kuhn, o paradigma não está habilitado a resolver todos os quebra-cabeças, todos os enigmas e as anomalias nascidos dele mesmo, mas dado o reduzido interesse da ciência normal em produzir grandes novidades, seja no domínio dos fatos ou da teoria, a ciência normal progride confirmando o paradigma de maneira ordenada, não-dramática, gradativa, isto é, por acumulação.

Se todos os filósofos da ciência são unânimes em afirmar que o trabalho de pesquisa científica se inicia com fundamento no conhecimento 
pré-existente, isto é, nas teorias estabelecidas, nem todos concordam, sobretudo Karl Popper, que a ciência progride por verdadeiros saltos qualitativos, isto é, por revoluções que as substituem por outras. Popper, por exemplo, afirma que a atividade científica deve ser compreendida fundamentalmente como atividade crítica, o que lhe confere o caráter de atividade de revolução permanente. A filosofia de Thomas Kuhn, entretanto, leva-nos inevitavelmente a admitir o fideísmo nas verdades científicas estabelecidas, o que acaba por condicionar negativamente a pesquisa científica e, em especial, a sociológica. O fideísmo é a fonte do dogmatismo que, por sua vez, é a negação do racionalismo crítico. O fideísmo - situação reconhecida pelo próprio Kuhn como indesejável, porém inevitável - dificulta o avanço nos trabalhos científicos, na medida em que impede o desenvolvimento da crítica constante e interminável das verdades estabelecidas como científicas. O pensamento esbarra com o caráter sagrado dos dogmas científicos e está destinado a repetir-se melancolicamente, aprisionado no espaço fechado do próprio paradigma.

Ressalte-se, no entanto, e uma vez mais: as teorias são os olhos do cientista. Apontam o que é, de fato, significativo na infinitude caótica da realidade que elas ordenam; definem-lhe as características e criam o vocabulário próprio para identificá-las; formulam os principais problemas da investigação; fundamentam as hipóteses de pesquisa; determinam os procedimentos a seguir na busca do conhecimento e indicam as suas aplicações práticas, condição sine qua non para a leitura dos dados, dos fatos, dos fenômenos que nada dizem a não ser quando ordenados por uma teoria.

"O processo científico não vai dos "dados" à teoria, mas parte de determinadas informações, mediatizadas por uma problemática, para uma formulação epistemológica de problemas e, em seguida, desses problemas para um corpo de hipóteses que forma a base de toda teorização. A teoria hipotética suscita e produz "evidências fatuais que, reciprocamente, controlarão sua validade. Em última instância, a razão de ser das teorias científicas (De Bruyne, Paul et alli, 1982, p. 102) "é o papel que elas desempenham diante dos fatos: elas dão um quadro coerente dos fatos conhecidos, indicam como são organizados e estruturados, explicam-nos, preveem-nos e fornecem, assim, pontos de referência para a observação dos fatos novos. Sem os fatos, as teorias não teriam objeto." (O 'Neil, W.M., 1972, p. 280)

\section{Referências}

KUHN, Thomas - A Estrutura das Revoluções Científicas. São Paulo, Editora Perspectiva S.A., 1975

KUHN, Thomas - A Função do Dogma na Investigação Científica. In: DE DEUS, Jorge Dias - A Crítica da Ciência. Rio de Janeiro: Zahar Editores, 1974

POPPER, Karl - A Lógica da Pesquisa Científica. São Paulo: Editora Cultrix Ltda., 1972

POPPER, Karl - A Ciência Normal e Seus Perigos. In: LAKATOS, Imre e MUSGRAVE, Alan (org.) - A Crítica e o Desenvolvimento do Conhecimento. São Paulo: Editora Cultrix e Editora da Universidade de São Paulo, 1979

GOODE, W.J. e HATT, P.K. - Métodos em Pesquisa Social. São Paulo: Companhia Editora Nacional, 1972

BRUYNE, Paul et alli - Dinâmica da Pesquisa em Ciências Sociais. Rio de Janeiro: Francisco Alves Editora, 1977

O'NEIL, W.M. - Faits et Théories. Paris: Armand Colin, 1972

Submetido $10 / 2014$

Aprovado 12/2014 